\title{
KNOWING THE UNKNOWNS - FRESH INSIGHTS FROM AN UNKNOWN STOCK MARKET
}

\author{
Susan Sunila Sharma*, Naoyuki Yoshino**, and Farhad Taghizadeh-Hesary*** \\ * Corresponding Author. Deakin Business School, Deakin University, Australia. \\ E-mail: s.sharma@deakin.edu.au \\ **Keio University, Japan. Email: yoshino@econ.keio.ac.jp \\ *** Tokai University, Japan. Email: farhad@tsc.u-tokai.ac.jp
}

\begin{abstract}
The goal of our study is to examine the impact of natural disasters on the South Pacific Stock Exchange. We use daily time-series data for Fiji's stock market for the period 2000-2019. Our empirical framework is based on three factor regression models, namely the market model, the Fama and French three-factor model, and the Fama and French five-factor model. We find evidence that natural disasters in Fiji reduce abnormal returns in the most relevant five-factor model. Additionally, we provide evidence that different types of natural disasters have heterogeneous effects on Fiji's stock market. Our findings are further supported by a robustness check.
\end{abstract}

Keywords: Fiji; Stock market; Natural disaster; Political instability; EGARCH. JEL Classifications: G15.

\author{
Article history: \\ Received : May 01, 2021 \\ Revised : : September 04, 2021 \\ Accepted : : September 07, 2021 \\ Available online : December 31, 2021 \\ https://doi.org/10.21098/bemp.v24i4.1783
}




\section{INTRODUCTION}

In this paper we examine the effect of natural disasters on Fiji's stock market. There are a handful of studies which show that Fiji's stock market is affected by economic growth, exchange rate, money supply (M2), and political instability (see for example Puah and Jayaraman, 2007; Narayan and Smyth, 2013). Natural disasters have been identified by the central bank (Reserve Bank of Fiji, RBF, 2016) as one of the key bottlenecks for economic growth and development. The RBF (2016) annual report has shown concern that the progress of some of the sectors is affected by natural disasters. They specifically document sectors such as agriculture, insurance services, and tourism industry are prone to natural disasters. In order to combat adverse repercussion of natural disasters on the financial system, the RBF undertook numerous policy initiatives, such as expansion of mobile financial services, microfinance development and financial literacy awareness program (see RBF, 2016). However, none of the studies have examined the direct effects of natural disasters on the stock market empirically.

Our research hypothesis has roots in the literature that examines the impact of natural disasters on economic performance of Pacific Island Countries (PICs). In this regard, Lee, Zhang, and Nguyen (2018), Cabezon et al., (2015) and Narayan (2003) examine the impact of natural disasters on economic growth of PIC and conclude that severe disasters have a statistically significant and negative effect on economic growth. Lee, Zhang, and Nguyen (2018) and Cabezon et al., (2015) further document that natural disasters lead to a deterioration of the fiscal and trade balance while Narayan's (2013) study shows that cyclones also negatively affect private income, consumption, savings, and real national welfare of PICs. The focus of these studies is not on the stock market, however, we hypothesis that if natural disasters negatively affect economic growth, it will also have a negative impact on stock market. This is because it is documented by Puah and Jayaraman (2007) that Fiji's stock prices are positively related to economic growth. Therefore, in Fiji's case, if natural disasters have a significant and negative impact on economic growth then it will likely reduce business activities and hence profits, which will be reflected in abnormal returns.

Moreover, the main reason for examining the impact of natural disasters on Fiji's stock exchange stems from the frequency and intensity of extreme weather conditions in the Pacific Island region due to the global warming and climate change (see for instance Lee et al, 2018; Cabezon et al., 2015; Narayan, 2003). Therefore, we are more interested in knowing the unknowns of a less researched stock market, namely the Fijian one. The Fiji Islands have a warm tropical climate throughout the year. This hot and humid weather, together with Fiji's South Pacific location, invites many natural disasters, such as tropical cyclones, flood, droughts, and earthquakes. Of these natural disasters, Fiji is more prone to a tropical type of hurricane which is the most common and the most dangerous disaster in the Pacific region. Fiji's cyclone season covers half the year, from November to April. The impact of severe cyclones in Fiji is enormous, as they bring massive rainfall and high-speed winds accompanied by low pressure, leading to a rise in sea levels. The aftermath of every cyclone in Fiji is unpredictable, as it leads to the destruction of houses, roads, and other infrastructure (see Esler, 2016). The flooding due to these cyclones causes massive loss of vegetation, land erosion, coastal inundation, 
and water pollution ${ }^{1}$. Over the last 20 years, Fiji has experienced numerous tropical cyclones. For instance, in December 2007, cyclone Daman adversely affected the northern part of Fiji and destroyed many houses. In January 2008, cyclone Gene caused disruption in the capital city, Suva, leading to widespread flooding and blackouts; it took the lives of eight people. Cyclone Evan, unleashed on Fiji's main island (Viti Levu) in December 2012, destroyed a number of houses and caused widespread power and water outages. Additionally, cyclone Winston was the most powerful cyclone to hit the South Pacific islands in recorded history. This cyclone made landfall in Fiji on 20 Feb 2016 with its peak intensity of Category 5. Fiji had never previously experienced such a tropical cyclone-it caused damage of around USD 650 million $^{2}$. According to the National Disaster Management Office (NDMO), tropical cyclone Winston significantly damaged 16,757 houses, demolished 9,173 more, partially damaged 29,000 others, and rendered around 131,000 Fijians homeless (which is about $15 \%$ of the country's population).

Given this background of Fiji, we use daily time-series data over the period 04 January 2000 to 31 January 2019 to examine the impact of natural disasters on Fiji's stock market abnormal returns. ${ }^{3}$ We employ an Exponential Granger Autoregressive Conditional Heteroskedasticity (EGARCH) model. Our model specification is based on three factor regression models, which are:

(1) The Market Model (MM), where Fiji's stock market excess returns (FJExR) are regressed on stock market excess returns of the Asia-Pacific region (MKR);

(2) The Fama and French (1993) three-Factor Model (3-FM), where FJExR is regressed on MKR, Small Minus Big market capitalization (SMB), and High Minus Low book-to-market-ratio (HML) of the Asia-Pacific region; and

(3) The Fama and French (2015) five-factor model (5-FM), where FJExR is regressed on MKR, SMB, HML, Robust Minus Weak operating profitability (RMW), and Conservative Minus Aggressive investments (CMA) of the Asia-Pacific region. In addition, we include a dummy variable for Natural Disasters (ND) in all above three factor regression models to examine the impact of natural disasters on Fiji's abnormal returns.

Our above-mentioned approaches lead to the following main findings. First, our results imply that of the three factor regression models, the most relevant, namely the 5-FM model, produces results as per our expectations. More specifically, we find that the impact of natural disasters on Fiji's stock market is a reduction in abnormal returns by $0.08 \%$. Secondly, we disaggregate these natural disasters into three types - storms (tropical cyclones), floods, and droughts - to examine whether the impact of different types of natural disasters are homogenous. Our findings reveal heterogeneous effects of these different types of natural disasters on abnormal returns. More specifically, we find that storms (tropical cyclones)

\footnotetext{
1 See the following link for more detail: Cyclone-Winston-Env-Issues-2-March-2016.pdf

2 https://www.abc.net.au/news/2016-02-26/cyclone-winston-damage-bill-reaches-650-milliondollars/7201846.

3 According to the SPSE 2018 annual report, the number of trades reported to be 1,771 for the year end. This is an increase of around $23.5 \%$ compared to the number of trades recorded in 2017 . Additionally, it is noted that the total volume traded stood at $13,963,159$ shares which resulted into $\$ 24,884,808$ in total value traded.
} 
have an adverse (or negative) effect on Fiji's stock market compared to floods and droughts.

Our study contributes to the literature that examines the impact of natural disasters on stock markets. Kong et al. (2021) examines the effect of earthquake on China's analysts' earnings forecasts and stock returns and conclude that earthquakes do not significantly affect firms' earnings and stock returns. Worthington and Valadkhani (2004) examine the impact of natural disasters on the Australian equity market. Their findings indicate that natural events, such as bushfires, cyclones, and earthquakes have a major effect on Australia's stock market returns, while events such as severe storms and floods have no impact. Additionally, Bourdeau-Brien and Kryzanowski (2017) test whether natural disasters have a significant impact on stock returns and volatilities of American firms. They conclude that a small proportion of catastrophes can have a significant impact on stock returns. On the other hand, Worthington (2008), using a GARCHmean model, finds no significant effect of natural events and disasters on Australia's stock market returns. Worthington's findings are further corroborated by Wang and Kutan (2013) who use a GARCH model and document no significant change in American and Japanese stock market returns following natural disasters. These studies are generally skewed to the developed and emerging economies and the conclusions drawn are inconsistent. To our best knowledge, there is no such study which considers the impact of natural disasters on underdeveloped or developing financial stock market. Therefore, our study is the first to consider an underdeveloped financial market and we are first to document that even though the size of the country, Fiji, and its stock exchange is small, the impact of natural disasters on the stock exchange is statistically significant.

Finally, we also conduct a robustness check of our results by controlling for the impact of Fiji's political instability. Fiji has experienced two coups during the sample period (2000 - 2019) of our study. A group led by George Speight entered the nation's Parliament buildings on 19 May 2000 and held the then Prime Minister Mahendra Chaudhary and other parliamentarians and their staff hostage for around 56 days. The second coup took place on 05 December 2006, when Commodore Frank Bainimarama staged a coup against the Government of the then Prime Minister Laisenia Qarase and declared himself as the Acting President of Fiji. A more comprehensive context of Fiji's coup culture can be found in Narayan and Smyth (2013). They examine whether political instability contributes to price clustering on Fiji's stock market. Their results imply that political instability induces stock price clustering on the SPSE. Therefore, it is essential for us to check the robustness of our results by including a dummy variable for Political Instability in all factor regression models. Our results remain the same. We see a negative impact of natural disasters on Fiji's stock market excess returns. Additionally, in all factor regression models, we report that political unrest has a statistically significant impact on Fiji's stock market excess returns.

The rest of the paper is structured as follows. In the next section, the theoretical model of the paper is provided. In Section III we describe our data and provide the empirical model specification. In the penultimate section, empirical results are presented and discussed. In the final section, we provide concluding remarks and policy implications. 


\section{THEORETICAL MODEL}

In this section, we develop a theoretical model which forms the foundation of our empirical model. We begin by specifying the following model where excess stock market returns are considered as a function of economic performance of a country:

$$
\text { Excess return } P_{S}-\bar{P}_{S}=P_{S}(Y(N D, Z, X))-\bar{P}_{S}(\bar{Y}(\bar{Z}, \bar{X}))
$$

In Equation (1), $P_{S}$ denotes stock price and $\bar{P}_{S}$ is the fundamental stock value. $Y$ denotes the Gross Domestic Product (GDP) which is affected by the Natural Disaster $(N D)$ and by further risk factors $(Z)$. $X$ is the vector of other economic variables affecting the level of GDP. The second part of Equation $(1),\left(\bar{P}_{S}(\bar{Y}(\bar{Z}, \bar{X}))\right.$, shows that the fundamental stock value is determined by the fundamental value of GDP which is a function of average value of risk factors and average value of other economic variables and $\overline{N D}=0$.

$$
Z=\{M K R, S M B, H M L, R M W, C M A\}
$$

$M K R, H M L, S M B, R M W$, and $C M A$, represent the five risk factors proposed by Fama and French (2015).

$$
P_{S}-\bar{P}_{S}=f(Y(N D, Z, X))-\bar{Y}((\bar{Z}, \bar{X}))
$$

Equation (3) shows that the GDP gap affects the stock market return compared to the fundamental value (excess return).

$$
\begin{aligned}
& \frac{d\left(P_{S}-\bar{P}_{S}\right)}{d N D}=\frac{\partial(f)}{\partial(Y-\bar{Y})} \cdot \frac{\partial(Y-\bar{Y})}{\partial N D} \\
& \frac{d\left(P_{S}-\bar{P}_{S}\right)}{d Z}=\frac{\partial(f)}{\partial(Y-\bar{Y})} \cdot \frac{\partial(Y-\bar{Y})}{\partial Z}
\end{aligned}
$$

Equations (4) - (5) show how excess return of the stock price are respectively affected by Natural Disasters (ND) and other risk factors (Z).

We carried out a Taylor expansion of Equation (3) to obtain Equation (6):

$$
P_{S}-\bar{P}_{S}=\alpha_{N D}(N D-\overline{N D})+\alpha_{Z}(Z-\bar{Z})+\alpha_{X}(X-\bar{X})
$$

Equation (6) shows that natural disaster occurrence affects the excess return on stock. Furthermore, other risk factors and economic factors are also affecting the excess return. Our empirical model in the following section is derived from Equation (6). In the empirical parts, for simplicity, we assume that other economic factors $(X)$ are in normal situation, hence we only focus on natural disasters and other risk factors as determining factors of excess returns. 


\section{DATA AND EMPIRICAL MODEL SPECIFICATION}

\section{A. Data}

We use daily time-series market capitalization-weighted price index for Fiji over the period 04 January 2000 to 31 January 2019. Data for the Fijian stock market is quite restricted and therefore our sample size is dictated by data availability. We have also extracted price index data for Australia from DataStream database. Additionally, we have used risk factors from the five-Factor Model proposed by Fama and French (2015). These five factors include $M K R, S M B, H M L, R M W$, and $C M A$ for the Asia-Pacific region. We extracted data for Fiji's natural disasters from the International Disaster Database published by the Centre for Research on the Epidemiology of Disasters (EM-DAT). Further detail on data for natural disasters and the construction and source of each variable is provided in Tables 1 and 2, respectively.

Table 1.

\section{An Overview of Natural Disasters}

This table provides an overview of natural disasters which affected Fiji over the period 1972 - 2018. Source: EM-DAT: The Emergency Events Database - Universite catholique de Louvain (UCL) - CRED, D. Guha-Sapir - www.emdat.be, Brussels, Belgium (Created: 14 April 2019).

\begin{tabular}{|c|c|c|c|c|c|}
\hline \multicolumn{6}{|c|}{ Panel A: Fiji's Natural Disasters } \\
\hline Date & \multicolumn{2}{|l|}{ Type } & Total Affected & \multicolumn{2}{|c|}{ Total Damage (‘000 US\$) } \\
\hline $24 / 10 / 1972$ & \multicolumn{2}{|l|}{ Storm } & 120000 & \\
\hline $1 / 03 / 1983$ & \multicolumn{2}{|l|}{ Storm } & 200014 & \multicolumn{2}{|r|}{50000} \\
\hline 00---1983 & \multicolumn{2}{|l|}{ Drought } & & \multicolumn{2}{|r|}{30000} \\
\hline 17/01/1985 & \multicolumn{2}{|l|}{ Storm } & 100000 & \multicolumn{2}{|r|}{73000} \\
\hline $12 / 04 / 1986$ & \multicolumn{2}{|l|}{ Flood } & 215000 & \\
\hline 2/01/1993 & \multicolumn{2}{|l|}{ Storm } & 160003 & \multicolumn{2}{|r|}{100000} \\
\hline 00-01-1998 & \multicolumn{2}{|l|}{ Drought } & 263455 & & \\
\hline $14 / 01 / 2003$ & \multicolumn{2}{|l|}{ Storm } & & \multicolumn{2}{|r|}{30000} \\
\hline 3/02/2007 & \multicolumn{2}{|l|}{ Flood } & & \multicolumn{2}{|r|}{30000} \\
\hline $8 / 01 / 2009$ & \multicolumn{2}{|l|}{ Flood } & & \multicolumn{2}{|r|}{43247} \\
\hline $14 / 03 / 2010$ & \multicolumn{2}{|l|}{ Storm } & & \multicolumn{2}{|r|}{39427} \\
\hline $29 / 03 / 2012$ & \multicolumn{2}{|l|}{ Flood } & & \multicolumn{2}{|r|}{72000} \\
\hline 00--09/2015 & \multicolumn{2}{|l|}{ Drought } & 67000 & \\
\hline 20/02/2016 & \multicolumn{2}{|l|}{ Storm } & 540558 & \multicolumn{2}{|r|}{600000} \\
\hline 2/04/2018 & Storm & & 89950 & \\
\hline $9 / 04 / 2018$ & Storm & & 89250 & & \\
\hline & Panel B: Sur & imary of & Natural Disaste & rs Statisti & \\
\hline $\begin{array}{l}\text { Disaster } \\
\text { Type }\end{array}$ & Disaster Subtype & $\begin{array}{l}\text { Events } \\
\text { Count }\end{array}$ & $\begin{array}{l}\text { Total } \\
\text { Deaths }\end{array}$ & $\begin{array}{c}\text { Total } \\
\text { Affected }\end{array}$ & $\begin{array}{c}\text { Total Damage (‘000 } \\
\text { US\$) }\end{array}$ \\
\hline Drought & Drought & 3 & 0 & 361455 & 30000 \\
\hline Earthquake & Ground movement & 2 & 0 & 0 & 0 \\
\hline Flood & -- & 3 & 30 & 233000 & 16500 \\
\hline Flood & Coastal flood & 1 & 4 & 0 & 0 \\
\hline Flood & Flash flood & 2 & 5 & 600 & 7000 \\
\hline Flood & Riverine flood & 6 & 32 & 31225 & 162747 \\
\hline Storm & -- & 1 & 1 & 3369 & 25000 \\
\hline Storm & Tropical cyclone & 38 & 567 & 1556562 & 1102486 \\
\hline
\end{tabular}


Table 2.

Variable Description

\begin{tabular}{|c|c|c|c|}
\hline Abbreviations & Full form & Data description & Source \\
\hline FJPI & $\begin{array}{l}\text { Market Cap- } \\
\text { weighted Price } \\
\text { Index }\end{array}$ & Market cap-weighted price index & $\begin{array}{c}\text { South Pacific Stock } \\
\text { Exchange http://spse. } \\
\text { com.fj/Market-Statistics/ } \\
\text { SPSE-Indices/Indices- } \\
\text { Report.aspx } \\
\end{array}$ \\
\hline AU3MTBill & $\begin{array}{l}\text { Australia 3-month } \\
\text { Treasury Bill Yield }\end{array}$ & Risk-free rate for Australia. & $\begin{array}{l}\text { Global Financial } \\
\text { Database }\end{array}$ \\
\hline AUPI & $\begin{array}{l}\text { Australia Price } \\
\text { Index }\end{array}$ & Australia Price Index & Datastream \\
\hline$F J R$ & $\begin{array}{c}\text { Fiji ‘s stock market } \\
\text { returns }\end{array}$ & $F J R=\left(\log \left(F J S P / F J S P_{t-1}\right)\right)^{*} 100$ & Authors calculation \\
\hline FJExR & $\begin{array}{l}\text { Fiji's stock market } \\
\text { excess returns }\end{array}$ & FJExR=FJR-AU3MTBill & Authors calculation \\
\hline AUR & $\begin{array}{l}\text { Australia stock } \\
\text { market returns }\end{array}$ & AUR $=\left(\log \left(A U P I / A U P I_{t-1}\right)\right)^{*} 100$ & Authors calculation \\
\hline AUExR & $\begin{array}{l}\text { Australia stock } \\
\text { market excess } \\
\text { returns } \\
\end{array}$ & AUExR=AUR-AU3MTBill & Authors calculation \\
\hline$M K R$ & $\begin{array}{l}\text { Asia-Pacific } \\
\text { (excludes Japan) } \\
\text { stock market } \\
\text { excess returns }\end{array}$ & $\begin{array}{l}\text { Market is the return on a region's } \\
\text { value-weight market portfolio minus } \\
\text { the U.S. one month T-bill rate. }\end{array}$ & $\begin{array}{l}\text { Kenneth R. French data } \\
\text { library http://mba.tuck. } \\
\text { dartmouth.edu/pages/ } \\
\text { faculty/ken.french/ } \\
\text { data_library.html }\end{array}$ \\
\hline$H M L$ & $\begin{array}{l}\text { Asia-Pacific } \\
\text { (excludes Japan) } \\
\text { High Minus Low. }\end{array}$ & $\begin{array}{l}\text { High Minus Low is the average return } \\
\text { on the two value portfolios minus } \\
\text { the average return on the two growth } \\
\text { portfolios. }\end{array}$ & $\begin{array}{l}\text { Kenneth R. French data } \\
\text { library http://mba.tuck. } \\
\text { dartmouth.edu/pages/ } \\
\text { faculty/ken.french/ } \\
\text { data_library.html } \\
\end{array}$ \\
\hline$S M B$ & $\begin{array}{c}\text { Asia-Pacific } \\
\text { (excludes Japan) } \\
\text { Small Minus Big. }\end{array}$ & $\begin{array}{l}\text { Small Minus Big is the average return } \\
\text { on the nine small stock portfolios } \\
\text { minus the average return on the nine } \\
\text { big stock portfolios. }\end{array}$ & $\begin{array}{l}\text { Kenneth R. French data } \\
\text { library http://mba.tuck. } \\
\text { dartmouth.edu/pages/ } \\
\text { faculty/ken.french/ } \\
\text { data_library.html }\end{array}$ \\
\hline$R M W$ & $\begin{array}{c}\text { Asia-Pacific } \\
\text { (excludes Japan) } \\
\text { Robust Minus } \\
\text { Weak. }\end{array}$ & $\begin{array}{l}\text { Robust Minus Weak is the average } \\
\text { return on the two robust operating } \\
\text { profitability portfolios minus the } \\
\text { average return on the two weak } \\
\text { operating profitability portfolios. }\end{array}$ & $\begin{array}{l}\text { Kenneth R. French data } \\
\text { library http://mba.tuck. } \\
\text { dartmouth.edu/pages/ } \\
\text { faculty/ken.french/ } \\
\text { data_library.html }\end{array}$ \\
\hline$C M A$ & $\begin{array}{l}\text { Asia-Pacific } \\
\text { (excludes Japan) } \\
\text { Conservative } \\
\text { Minus Aggressive. }\end{array}$ & $\begin{array}{l}\text { Conservative Minus Aggressive } \\
\text { is the average return on the two } \\
\text { conservative investment portfolios } \\
\text { minus the average return on the two } \\
\text { aggressive investment portfolios. }\end{array}$ & $\begin{array}{l}\text { Kenneth R. French data } \\
\text { library http://mba.tuck. } \\
\text { dartmouth.edu/pages/ } \\
\text { faculty/ken.french/ } \\
\text { data_library.html }\end{array}$ \\
\hline
\end{tabular}

\section{B. Model Specification}

In order to examine the effect of natural disasters on Fiji's stock market excess returns, we adopt the EGARCH model specification from Bourdeau-Brien and Kryzanowski (2017). Our three time-series EGARCH $(1,1)$ models take the following forms: 
Market Model (MM):

$$
F J E x R_{t}=\alpha+\beta_{1} M K R_{t}+\delta N D_{t}+\varepsilon_{t}
$$

Fama-French three-Factor Model (3-FM):

$$
\text { FJExR }_{t}=\alpha+\beta_{1} M K R_{t}+\beta_{2} H M L_{t}+\beta_{3} S M B_{t}+\delta N D_{t}+\varepsilon_{t}
$$

Fama-French five-Factor Model (5-FM):

$$
\text { FJExR }_{t}=\alpha+\beta_{1} M K R_{t}+\beta_{2} H M L_{t}+\beta_{3} S M B_{t}+\beta_{4} R M W_{t}+\beta_{5} C M A_{t}+\delta N D_{t}+\varepsilon_{t}
$$

The conditional variance equation in all the above three models is of the following form:

$$
\begin{aligned}
& \ln \left(\sigma_{t}^{2}\right)=\alpha_{0}+\theta \ln \left(\sigma_{t-1}^{2}\right)+\tau \frac{\varepsilon_{t-1}}{\sigma_{t-1}}+\omega\left(\frac{\left|\varepsilon_{t-1}\right|}{\sigma_{t-1}}-E \frac{\left|\varepsilon_{t-1}\right|}{\sigma_{t-1}}\right) \\
& \varepsilon_{t}=z_{t} \sigma_{t}, z_{t} \sim N(0,1)
\end{aligned}
$$

Equations (7) - (9) represent the conditional mean model. Here, FJExR represents Fiji's stock market excess returns that is computed by subtracting Australia's three-month T-bill rate from Fiji's stock market returns (FJSR,where $F J S R=\log \left(\left(F J P I / F L P I_{t-1}\right)^{*} 100\right)$. ND is a dummy variable which is equal to value one during the event period (one to five days) of natural disaster and zero otherwise. $M K R, H M L, S M B, R M W$, and $C M A$, represent the five risk factors proposed by Fama and French (2015).

Moreover, Equation (10) specifies the EGARCH structure for the conditional variance $\left(\sigma_{t}^{2}\right)$ of the residuals. $\alpha_{0}$ determines the unconditional variance; $\theta$ and $\tau$ are coefficients associated with the ARCH and GARCH terms, respectively. Finally, $\omega$ captures the impact of leverage effect.

\section{EMPIRICAL RESULTS}

\section{A. Preliminary Analysis}

Here we begin by providing an overview of natural disasters which affected Fiji over the period 1972 to 2018 (see Table 1). In total, there is a record of 16 natural disaster events which affected Fiji during this period. These natural disasters are categorized into three types - namely storms, floods, and droughts. The occurrence of tropical cyclones (storms) in Fiji is more prevalent compared to events such as floods and droughts. In our study, we consider natural disaster events since 2000 and we note that in total there are five events of storms, three events of flooding, and one occurrence of drought. The storms affected Fiji on 14 Jan 2003, 14 Mar 2010, $20 \mathrm{Feb}$ 2016, $02 \mathrm{Apr} 2018$, and 09 Apr 2019. The events of flooding took place on $03 \mathrm{Feb}$ 2007, 08 Jan 2009, and 29 Mar 2012, whereas a drought was recorded in Sept 2015. Of all these events, tropical cyclone Winston, which hit Fiji on 20 Feb 2016, was the most severe and caused damage amounting to approximately USD 
600 million. It struck Fiji at an intense Category 5 which led the Fijian Government to declare a state of emergency for around 60 days.

Table 3.

Descriptive Statistics

This table reports the selective descriptive statistics for variables used in our empirical analysis. The statistics include the mean value, Standard Deviation (Std. Dev.), skewness, kurtosis, and Jarque-Bera (JB) test $p$-values which examines the null hypothesis of "normal distribution".

\begin{tabular}{lccccc}
\hline & Mean & Std. Dev. & Skewness & Kurtosis & JB $p$-value \\
\hline FJR & 0.0239 & 0.5759 & 0.0320 & 91.8184 & 0.0000 \\
FJExR & -0.1610 & 0.5759 & 0.0320 & 91.8184 & 0.0000 \\
AUExR & -0.1721 & 0.9628 & -0.4935 & 9.0046 & 0.0000 \\
MKR & 0.0273 & 1.0634 & -0.5451 & 12.7197 & 0.0000 \\
$H M L$ & 0.0280 & 0.5493 & 0.1399 & 5.4321 & 0.0000 \\
SMB & -0.0109 & 0.5357 & -1.0543 & 14.6045 & 0.0000 \\
RMW & 0.0158 & 0.5031 & -0.0428 & 5.9076 & 0.0000 \\
CMA & 0.0174 & 0.4327 & 0.2562 & 9.3144 & 0.0000 \\
\hline
\end{tabular}

Next, we discuss some common descriptive statistics of data from Table 3. The most interesting variable here is Fiji's stock market Returns (FJR) because, to-date, very little is known about Fiji's stock market. We plot Fiji's market cap-weighted Price Index (FJPI) and its corresponding FJR in Figure 1. The plot for FJPI seems quite stable over the period 2000 - 2014, after which it was followed by an upward trend. We report a daily mean FJR of 0.02\% during the period Jan 2000 to Jan 2019. Fiji's mean stock market return in excess of the risk-free rate is $-0.16 \%$. We also note that kurtosis and skewness statistics indicate FJR and FJExR follow a non-normal distribution. This is further calibrated by the Jarque-Bera (JB) test which examines the null hypothesis of "normal distribution." The JB test $p$-values reported in the last column of Table 3 imply that we reject the null of normal distribution at the $1 \%$ statistical significance level for both the FJR and FJExR series.

Additionally, we report descriptive statistics for AUExR and five risk factors (namely, MKR, HML, SMB, RMW, and CMA). The daily mean AUExR is $-0.17 \%$. The JB test results reveal that we reject the null hypothesis of normal distribution for AUExR and for all five risk factors. 


\section{Figure I: Plot of Fiji's Stock Returns}

In this figure, we plot Fijis market cap-weighted price index (FJPI) and Fijis stock returns (FJR), respectively. Our data covers the period $2000-2018$.
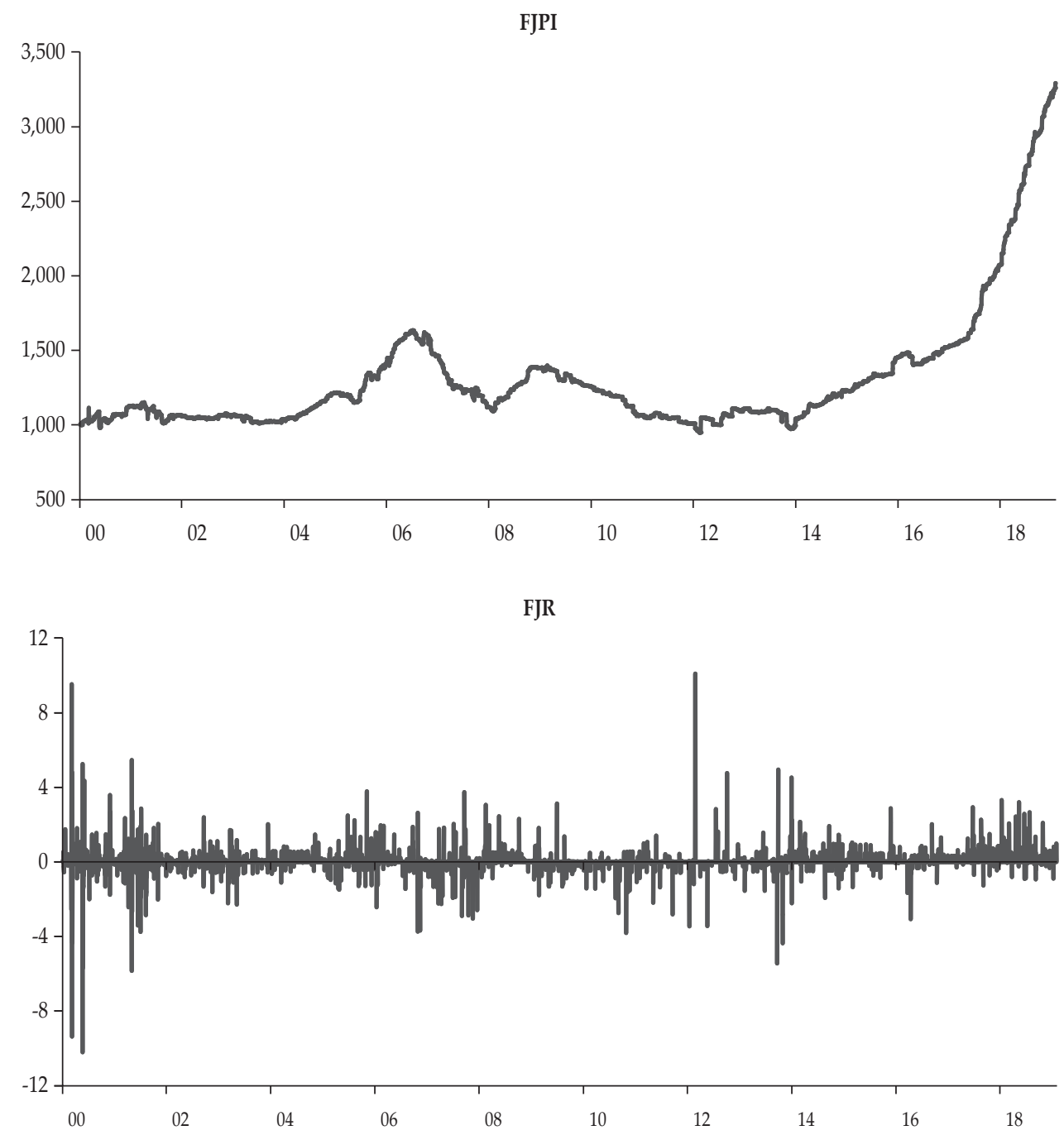
Table 4.

\section{Persistency, Unit Root, and Heteroskedasticity Test Results}

This table reports some preliminary analysis of sample data. Here, we report first-order autoregressive (AR(1)) coefficient of all variables and as well as results for ADF unit root test in columns 2 and 3, respectively. The ADF unit root test examines the null hypothesis of "unit root". We examine the ADF test using a maximum of 8 lags and then Schwartz Information Criterion is used to determine the optimal lag length. The heteroskedasticity test is performed based on Lagrange Multiplier test which examines the null hypothesis of "no ARCH" at the lag of 6. We do this by estimating an AR (1) model of all variables.

\begin{tabular}{lcccccc}
\hline & \multirow{2}{*}{ AR (1) } & \multicolumn{3}{c}{ ADF Unit Root Test } & \multicolumn{2}{c}{ Heteroskedasticity Test } \\
\cline { 3 - 7 } & & t-statistics & Lag length & $p$-value & ARCH (6) & $p$-value \\
\hline FJR & -0.2498 & -38.8367 & 2 & 0.0000 & 186.7578 & 0.0000 \\
FJExR & -0.2498 & -38.8367 & 2 & 0.0000 & 186.7578 & 0.0000 \\
AUExR & -0.0258 & -72.4184 & 0 & 0.0001 & 955.1192 & 0.0000 \\
MKR & 0.1225 & -62.3722 & 0 & 0.0001 & 1224.793 & 0.0000 \\
HML & 0.0719 & -65.6260 & 0 & 0.0001 & 509.1789 & 0.0000 \\
SMB & 0.0697 & -36.6859 & 3 & 0.0000 & 819.3408 & 0.0000 \\
RMW & 0.0043 & -70.2306 & 0 & 0.0001 & 453.1346 & 0.0000 \\
CMA & 0.0908 & -64.3959 & 0 & 0.0001 & 837.7169 & 0.0000 \\
\hline
\end{tabular}

Moreover, we also examine persistency, unit root, and presence of heteroskedasticity, which are some salient feature of time-series data and they need to be pre-determined so that they can be adequately controlled in our regression models. These results are reported in Table 4 . We begin by examining the persistency of each variable. To do so, we estimate an autoregressive model of order one $(\mathrm{AR}(1))$ and check whether an $\mathrm{AR}(1)$ coefficient is close to value one. The AR(1) coefficient for all variables are recorded less than 0.5 , which suggests our data series is not persistent. Next, we test a null hypothesis of unit root using an Augmented Dickey Fuller (ADF) unit root test. We report the ADF test statistics, their corresponding $p$-values, and as well as their estimated lag lengths, which are obtained using the Schwarz Information Criterion (starting with a maximum of eight lags) in column 3. We comfortably reject the null hypothesis of unit root at the $1 \%$ statistical significance level for all variables. This implies all our data follows a stationary process which is also a prerequisite of estimating an EGARCH model.

Finally, we consider the heteroskedasticity test. We determine the presence of heteroskedasticity by first estimating an AR(1) model of all variables and we subject the residuals to an Autoregressive Conditional Heteroskedasticity $(\mathrm{ARCH})$ test at a lag of six. The ARCH test is a Lagrange Multiplier (LM) based test which examines the null hypothesis of "no ARCH." We report results for heteroskedasticity test in final column of Table 4 . The $p$-value for the LM test indicates statistical significance at $1 \%$ level for all variables. In other words, we reject the null of "no $\mathrm{ARCH}^{\text {" for }}$ all variables which does imply that we do need to control for heteroskedasticity in our regression models. Thus, this is the main motivation for using an EGARCH model over an Ordinary Least Squares (OLS), because ARCH-type models control for heteroskedasticity. 


\section{B. Main Findings}

Our focus here is on estimated abnormal returns (resulting alpha) from our proposed three models (MM, 3-FM, and 5-FM). These factor regression models contain the alpha which we use to judge abnormal returns from Fiji's stock market. Table 5 contains two sets of results. Results reported in Panel A do not include a ND dummy variable in factor regression models, whereas those reported in Panel B do include a ND dummy variable in all three factor models. These two sets of results, when compared, allow us to ascertain whether natural disasters have any adverse effect on abnormal returns. We find that abnormal returns are all statistically different from zero at the $1 \%$ level of significance.

Another important observation is the change in the magnitude of abnormal returns obtained from those three factor-regression models. To see this, we compute the percentage change in abnormal returns obtained from factor regression models specified in Panel A versus models considered in Panel B. The percentage difference between abnormal returns obtained from the three factor regression models reported in Panels $\mathrm{A}$ and $\mathrm{B}$ are $0.18 \%,-0.03 \%$, and $-0.08 \%$ respectively. Our findings imply that the impact of natural disasters on Fiji's stock market excess returns is positive only when we consider a MM model where the abnormal returns increases by $0.18 \%$ per day. However, theoretically, we know that the MM is not the ideal risk-adjusted model. As more factors are modeled, the better are the observed abnormal returns. Therefore, we do not consider these abnormal returns obtained using the MM model seriously. The abnormal returns obtained from the other factor-regression models, namely the 3-FM and 5-FM (most relevant) models, indicate that when the impact of natural disaster is considered in these models, the abnormal return reduces by $0.03 \%$ and $0.08 \%$ respectively. The implication is that stock market excess returns are not only dependent on riskfactors, but natural disasters in Fiji also have an impact on the stock market as they lead to a significant decrease in abnormal returns.

Next, we read results from Table 5. Here we disaggregate natural disasters into three major categories which are the most common forms of natural events in Fiji. These include: (i) storms (tropical cyclones); (ii) floods; and (iii) droughts. We now create three dummy variables for each type of natural disaster. Our empirical approach remains the same; however, we are more interested in seeing whether all three categories of natural events have the same or a different effect on Fiji's stock market. Thus, the ND dummy variable considered in factor regression models represents storms, floods, and droughts, and these results are respectively reported in Panels A, B, and C of Table 6. We find that, irrespective of the type of natural disaster, the resulting alphas (abnormal returns) from all factor regression models are negative and significant at $1 \%$ significance level. Next, we compute the percentage change in abnormal returns obtained from factor regression models specified in Panel A of Table 5 against models considered in Table 6. The percentage difference between abnormal returns obtained from factor regression models considered in Table 5 (Panel A) and Table 4 (Panel A) are - 0.11\% (MM), $0.57 \%(3-\mathrm{FM})$, and $-1.32 \%$ (5-FM), respectively. Our findings imply that the impact of storms on Fiji's stock market excess returns obtained from most relevant 5-FM reduces abnormal returns by $1.32 \%$. Next, we make similar comparison for the other natural events, namely floods and droughts. Again, we compare abnormal 


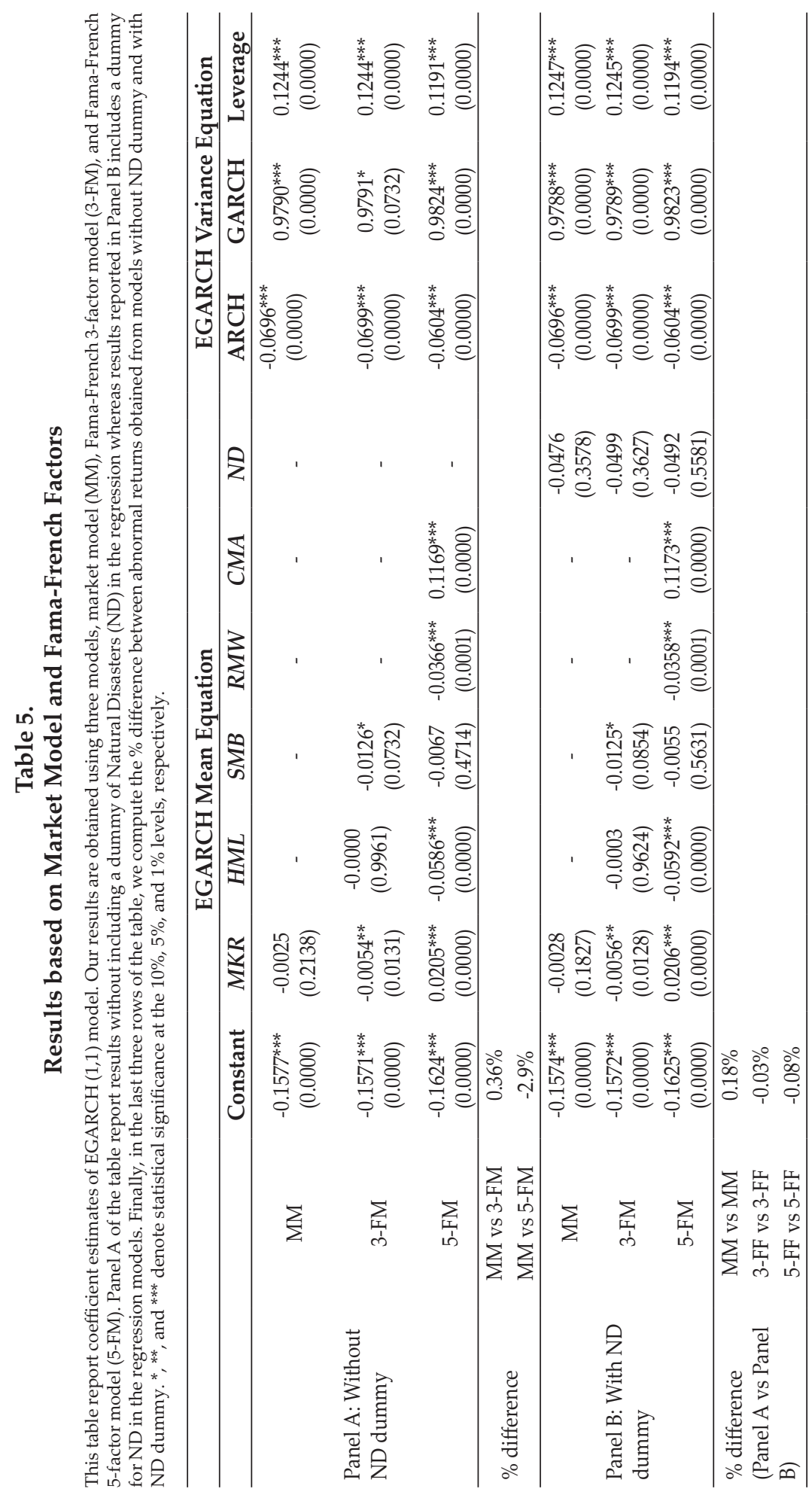




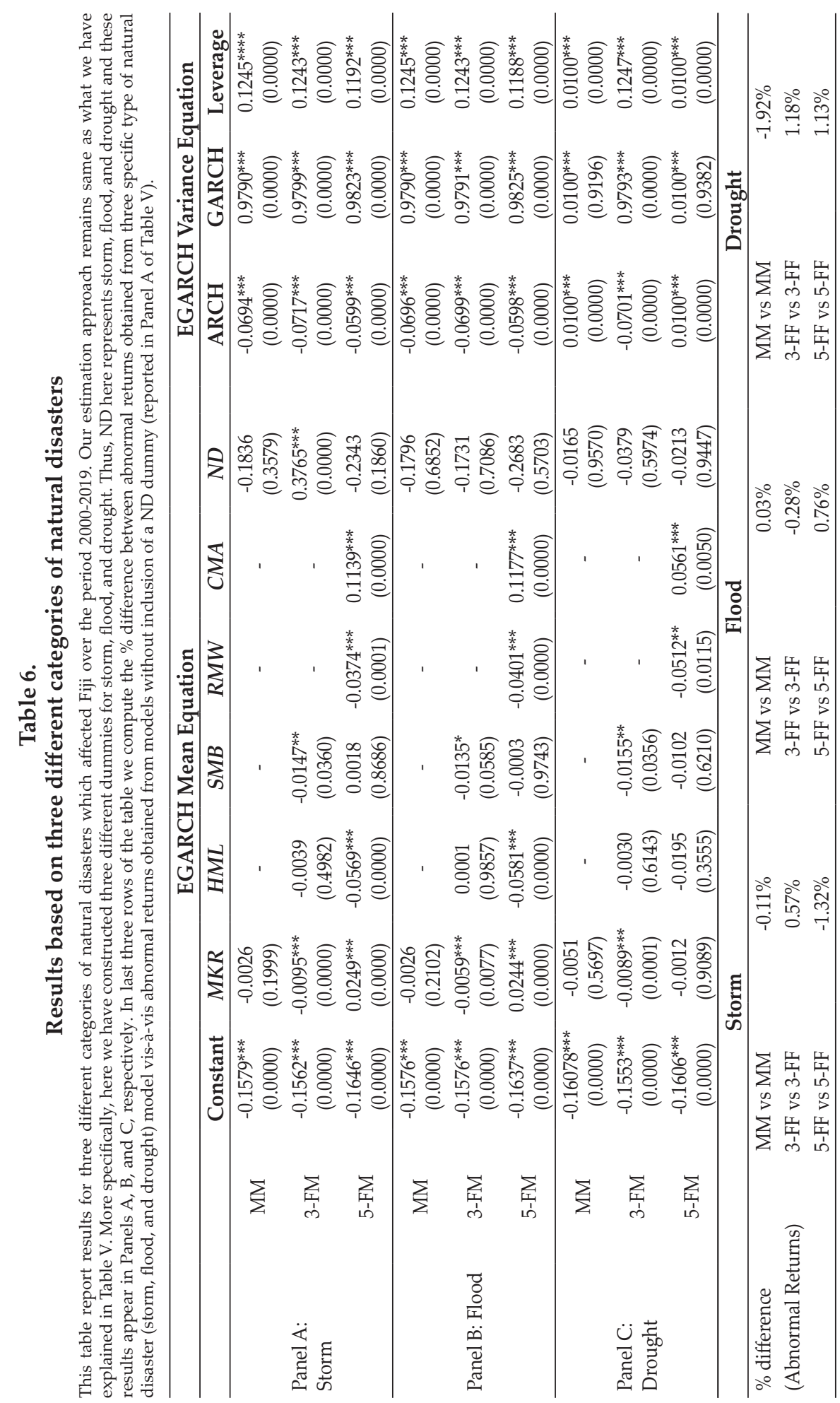


returns obtained from factor regression models (with no ND dummy) with abnormal returns obtained from factor regression models which include ND dummy for floods and droughts, respectively. The percentage change in abnormal returns obtained using the most relevant 5-FM for floods and droughts are $0.76 \%$ and $1.13 \%$, respectively. The abnormal returns obtained using factor regression models with an inclusion of floods and droughts, increase by $0.76 \%$ and $1.13 \%$, respectively. The implication is that storms have an adverse (or negative) effect on Fiji's stock market compared to floods and droughts. Thus, our findings imply that there is a heterogeneous effect of different categories of natural disasters on Fiji's stock market and not all types of natural events will adversely affect the stock market in the case of Fiji.

\section{Robustness Check}

As mentioned in the introduction section, Fiji experienced two coups during the period 2000 - 2019, therefore, it becomes essential to control for the effect of political unrest on the performance of Fiji's stock market. Thus, for robustness check, we include a dummy variable for Political Instability (PI) in all three factor regression models. Results reported in Table 7 are divided into two panels. In Panel A, we report results for all three factor regression models which do not contain ND dummy variable whereas Panel B contains results with an inclusion of ND dummy variable in all three factor models. Our results remain the same as earlier. First, we note that the PI dummy variable is statistically significant at $1 \%$ significance level in all factor regression models. Second, the abnormal returns obtained from most relevant Factor-regression Model (5-FM) indicate that when we control for political unrest in regression models, the abnormal return reduces by $3.64 \%$ because of natural disasters. It is also worth noting that the magnitude of the percentage change between abnormal returns obtained from models without controlling for political unrest is around $46 \%$ less than abnormal returns obtained when Fiji's political unrest is controlled in 5-FM. The implication here is very simple - political unrest in Fiji plays a very important role in examining the performance of Fiji's economy and this is clearly indicated in overall results reported in Table 7. 


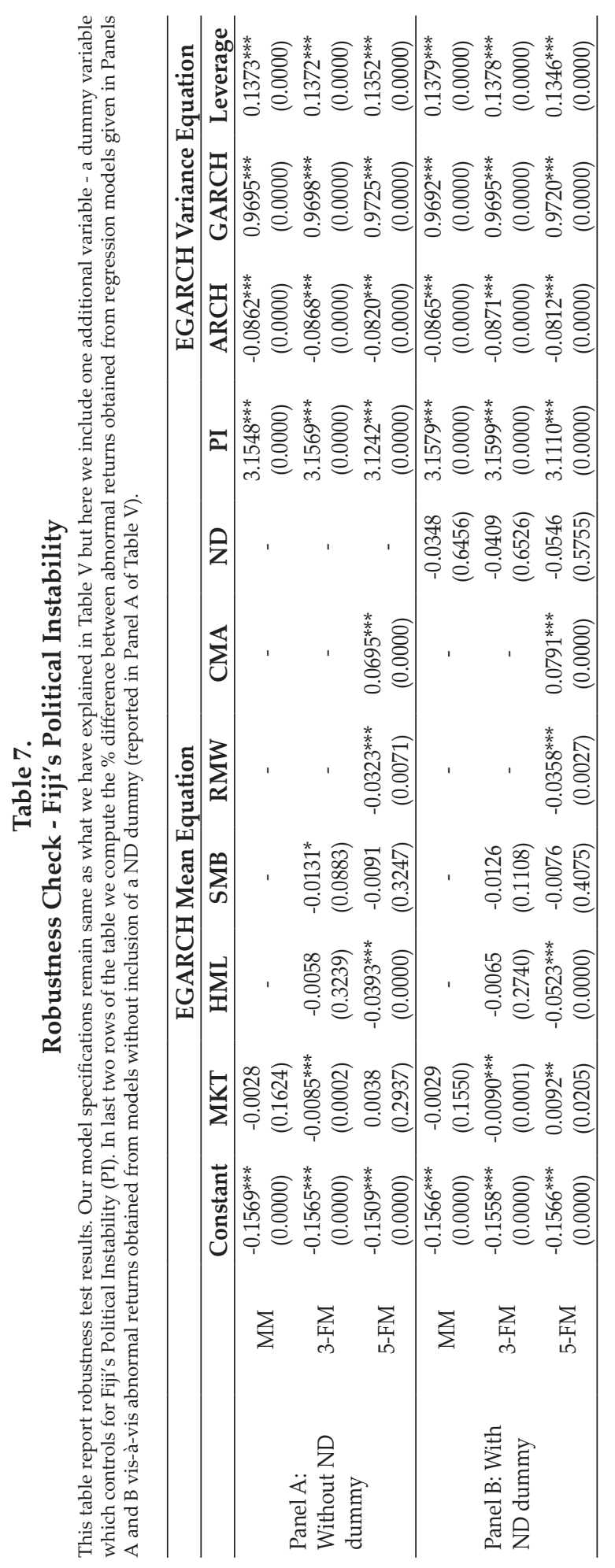




\section{CONCLUSION AND POLICY IMPLICATION}

This study examines the impact of natural disasters on Fiji's stock market using South Pacific Stock Exchange price data over the sample period, 04 January 2000 to 31 January 2019. We propose our empirical framework based on three factor regression models, namely the Market Model, the Fama and French three-Factor Model (3-FM), and the five-Factor Model (5-FM). We further include a dummy variable which captures natural disasters experienced by Fiji over the period 2000 - 2019 within these three factor regression models.

We conclude our study with some fresh insights from an unknown stock market. Our results, based on the most relevant Factor-regression Model (5-FM), suggest that the impact of natural disasters in Fiji leads to a decline in abnormal returns. Moreover, when we disaggregate natural disasters into three categories, namely storms, floods, and droughts, it is evidenced that storms are the only category which leads to this decline in the abnormal returns, whereas the same is not evidenced in the case of floods and droughts.

We also check the robustness of our results by including one more control variable in all three factor regression models. We construct a dummy variable for political unrest experienced by Fiji over the period 2000 - 2019. These political unrests include the 2000 and 2016 coups in Fiji. The coup culture of Fiji is not unknown and, therefore, controlling for its impact on the performance of Fiji's stock market is essentially important. Not to our surprise, our results remain the same.

In conclusion, natural disasters and other risk factors are important components of the small Pacific island economies which affect the performance of their stock markets. Hence, the policy implications of this study and for other small Pacific island economies cannot be overstated. Disasters reduce GDP levels, which has an adverse impact on the stock price index, which negatively affects the entire economy. It is very important to make these economies resilient to natural disasters, by spending more money on their prevention namely by "investing in Disaster Risk Reduction for resilience" through collaboration between public and private entities and "enhancing disaster preparedness for effective response" and to "Build Back Better in recovery, rehabilitation, and reconstruction" (UNISDR, 2019). The prevention policy for making these economies resilient includes the establishment of quality infrastructure (Taghizadeh-Hesary et al., 2020).

\section{REFERENCES}

Bourdeau-Brien, M., \& Kryzanowski, L. (2017). The Impact of Natural Disasters on the Stock Returns and Volatilities of Local Firms. Quarterly Review of Economics and Finance, 63, 259-270.

Cabezon, E., Hunter, L., Tumbarello, P., Washimi, K., \& Wu, Y. (2015). Enhancing Macroeconomic Resilience to Natural Disasters and Climate Change in the Small States of the Pacific. IMF Working Papers, 15/124, International Monetary Fund, Washington.

Esler, S. (2016). Post-disaster Needs Assessment: Tropical Cyclone Winston, February 20, 2016. Government of Fiji, Fiji. 
Fama, E. F., \& French, K. R. (2015). A Five-factor Asset Pricing Model. J Financ Econ, 116, 1-22.

Fama, E. F., \& French, K. R. (1993). Common Risk Factors in the Returns on Stocks and Bonds. Journal of Financial Economics, 33, 3-56.

Kong, D., Lin, Z., Wang, Y., \& Xiang, J. (2021). Natural Disasters and Analysts' Earnings Forecasts. Journal of Corporate Finance 66, 101860.

Lee, D., Zhang, H., \& Nguyen, C. (2018). The Economic Impact of Natural Disasters in Pacific Island Countries: Adaptation and Preparedness. IMF Working Papers, 18/108, International Monetary Fund, Washington.

Narayan, P. K. (2003). Macroeconomic Impact of Natural Disasters on a Small Island Economy: Evidence from a CGE Model. Applied Economics Letters, 10, 721-723.

Narayan, P. K., \& Smyth, R. (2013). Has Political Instability Contributed to Price Clustering on Fiji's Stock Market? Journal of Asian Economics, 28, 125-130.

National Disaster Management Office. (2006). Tropical Cyclone Winston Situation Report 95 (No. 95), National Disaster Management Office. Philippine, Fiji.

Natural Disaster Resiliency. ADBI Working Paper 991. Tokyo: Asian Development Bank Institute. Available: https://www.adb.org/publications/qualityinfrastructure-and-natural-disaster-resiliency

Puah, C-H., \& Jayaraman, T. K. (2007). Macroeconomic Activities and Stock Prices in a South Pacific Island Economy. International Journal of Economics and Management, 1, 229-244.

Reserve Bank of Fiji. (2016). January - July 2016 Report. Reserve Bank of Fiji. Fiji Islands.

Skidmore, M., \& Toya, H. (2007). Do Natural Disasters Promote Long-run Growth? Economic Inquiry, 40, 664-687.

Taghizadeh-Hesary, F., Sarker, T., Yoshino, N., Mortha, A., \& Vo, X. V. (2020). Quality Infrastructure and Natural Disaster Resiliency: A Panel Analysis of Asia and the Pacific. Economic Analysis and Policy, 69, 394-406. https://doi.org/10.1016/j.eap.2020.12.021

Wang, L., \& Kutan, A. M. (2013). The Impact of Natural Disasters on Stock Markets: Evidence from Japan and the US. Comparative Economic Study, pp. 55, 672-686.

Worthington, A. C. (2008). The Impact of Natural Events and Disasters on the Australian Stock Market: A GARCH-M Analysis of Storms, Floods, Cyclones, Earthquakes and Bushfires. Global Business and Economics Review, 10, 1-10.

Worthington, A. C., \& Valadkhani, A. (2004). Measuring the Impact of Natural Disasters on Capital Markets: An Empirical Application Using Intervention Analysis. Applied Economics, 36, 2177-2186. 